\title{
Modulation of $\mathrm{GABA}_{\mathrm{A}}$ Receptors by Hydrogen Ions Reveals Synaptic GABA Transient and a Crucial Role of the Desensitization Process
}

\author{
Jerzy W. Mozrzymas, ${ }^{1}$ Ewa D. Żarmowska, ${ }^{1}$ Maria Pytel, ${ }^{1}$ and Katarzyna Mercik ${ }^{1,2}$ \\ ${ }^{1}$ Department of Biophysics, Wroclaw Medical University, 50-368 Wroclaw, Poland, and ${ }^{2}$ Institute of Physics, Technical University of Wroclaw, 50-370 \\ Wroclaw, Poland
}

Protons are the most ubiquitous and very potent modulators of the biological systems. Hydrogen ions are known to modulate $\mathrm{GABA}_{\mathrm{A}}$ receptors $\left(\mathrm{GABA}_{\mathrm{A}} \mathrm{Rs}\right)$, but the mechanism whereby these ions affect IPSCs and the gating of $\mathrm{GABA}_{\mathrm{A}} \mathrm{Rs}$ is not clear. In the present study we examined the effect of protons on miniature IPSCs (mIPSCs) and found that hydrogen ions strongly affected both their amplitude and time course. To explore the underlying mechanisms with resolution adequate to the time scale of synaptic transmission, we recorded current responses to ultrafast $\mathrm{GABA}$ applications at various $\mathrm{pH}$. These experiments revealed that the major effect of protons on $\mathrm{GABA}_{\mathrm{A}} \mathrm{R}$ gating is a strong enhancement of desensitization and binding rates at increasing $\mathrm{pH}$. This analysis also indicated that desensitization rate is the fastest ligand-independent transition in the $\mathrm{GABA}_{\mathrm{A}} \mathrm{R}$ gating scheme. Although proton effects on the time course of mIPSCs and current responses to saturating [GABA] were similar, the $\mathrm{pH}$ dependencies of amplitudes were almost opposite. Our quantitative analysis, based on model simulations, indicated that this difference resulted from a much shorter receptor exposure to agonist in the case of mIPSCs. Modeling of IPSCs as current responses to brief exponentially decaying GABA applications was sufficient to reproduce correctly the $\mathrm{pH}$ dependence of mIPSCs, and optimal fit was obtained for peak [GABA] of 1.5-3 mM and a clearance time constant of $0.075-0.125$ msec. Our analysis indicates that, for these parameters of GABA transient, in control conditions (pH 7.2) mIPSCs are not saturated.

Key words: hydrogen ions; $\mathrm{GABA}_{\mathrm{A}}$ receptor; gating; mIPSC; synaptic GABA transient; synaptic receptor saturation; desensitization

\section{Introduction}

GABA is the major inhibitory neurotransmitter in the adult CNS (Cherubini and Conti, 2001), and the time course of GABAergic IPSCs is a key determinant of GABA-mediated inhibition. It is known that local proton concentration is regulated by a number of mechanisms, including enzymes (e.g., carbonic anhydrase), active transport, and cotransporters as well as passive ion transport (for review, see Kaila, 1994). As pointed out by Kaila and coworkers, the permeation of $\mathrm{HCO}_{3}^{-}$anions through the $\mathrm{GABA}_{\mathrm{A}}$ receptors $\left(\mathrm{GABA}_{\mathrm{A}} \mathrm{Rs}\right)$ may influence the $\mathrm{pH}$ level in the closest vicinity of the channel pore (Kaila et al., 1992; Kaila, 1994; Voipio et al., 1995). Hydrogen ions have been found to be a potent modulator of $\mathrm{GABA}_{\mathrm{A}}$ Rs. Pasternack et al. (1996) have reported that, in rat hippocampal neurons, current responses to high [GABA] were enhanced when proton concentration was increased, whereas the opposite was observed for currents elicited by low [GABA]. Qualitatively similar results have been obtained by

Received Feb. 21, 2003; revised June 12, 2003; accepted June 12, 2003.

J.W.M. and E.D.Ż. were supported by the Polish Committee for Scientific Research (KBN), Grant 6 P04A 00119 The Biog software was kindly given by Dr. H. Parnas, Hebrew University (Jerusalem, Israel). We thank Dr. Stefano Vicini for a critical reading of this manuscript.

Correspondence should be addressed to Dr. Jerzy W. Mozrzymas, Department of Biophysics, Wroclaw Medical University, ul. ChalubiПskiego 10, 50-368 Wroclaw, Poland. E-mail: mozrzy@biofiz.am.wroc.pl.

E. D. Zarmowska's present address: Department of Anesthesiology, University of Wisconsin Madison, 43 Medical Sciences Center, 1300 University Avenue, Madison, WI 53706.

Copyright $\odot 2003$ Society for Neuroscience $\quad 0270-6474 / 03 / 237981-12 \$ 15.00 / 0$
Krishek and Smart (2001) in granule cells and for $\mathrm{GABA}_{\mathrm{A}} \mathrm{Rs}$ expressed in Xenopus oocytes and encoded by poly $\left(\mathrm{A}^{+}\right)$mRNA from rat brain (Robello et al., 2000). Moreover, the proton effects were found to depend strongly on the $\mathrm{GABA}_{\mathrm{A}}$ receptor subtypes (Krishek et al., 1996, 1998).

The mechanism underlying the modulation of $\mathrm{GABA}_{\mathrm{A}}$ Rs by protons has not been elucidated fully. It is surprising that the current responses to nearly saturating [GABA] are enhanced strongly by lowering the $\mathrm{pH}$ (Pasternack et al., 1996), whereas neither the single-channel conductance nor the opening frequency is clearly affected by hydrogen ions (Krishek and Smart, 2001). Moreover, the characterization of $\mathrm{pH}$ effect on GABAergic IPSCs in relation to the modulation of $\mathrm{GABA}_{\mathrm{A}}$ receptor microscopic gating is essentially lacking. Recent studies have emphasized that extreme non-equilibrium conditions of synaptic receptor activation resulting from very fast agonist clearance have a crucial impact on the time course and pharmacological modulation of synaptic currents (Puia et al., 1994; Jones and Westbrook, 1995; Clements, 1996; Jones et al., 1998; Mozrzymas et al., 1999; Barberis et al., 2000). Thus the characterization of the receptor gating needs to be performed with a resolution adequate to the time scale of the synaptic events.

The goal of the present work was to characterize the effects of extracellular proton concentration on miniature IPSCs (mIPSCs) and to explore the underlying mechanisms in terms of microscopic gating of $\mathrm{GABA}_{\mathrm{A}}$ receptors. We found that protons 
strongly affected both the amplitude and the time course of mIPSCs in hippocampal neurons. The effect of hydrogen ions on $\mathrm{GABA}_{\mathrm{A}}$ receptors has been studied by analyzing the current responses to ultrafast GABA applications. Our results indicate that the modulation of mIPSCs is mainly attributable to an upregulation of desensitization and binding rates of $\mathrm{GABA}_{\mathrm{A}}$ Rs by decreasing proton concentration (increasing $\mathrm{pH}$ ). Our quantitative analysis enabled us to estimate the peak concentration $(1.5-3 \mathrm{~mm})$ and time of clearance of the synaptic GABA $(0.075-0.125 \mathrm{msec})$ and provided evidence that desensitization is the fastest process in the $\mathrm{GABA}_{\mathrm{A}} \mathrm{R}$ gating scheme.

\section{Materials and Methods}

Cell culture. Primary cell culture was prepared as described by Andjus et al. (1997). Briefly, postnatal day 2 (P2) to P4 Wistar rats were decapitated after being anesthetized with an intraperitoneal injection of urethane (2 $\mathrm{gm} / \mathrm{kg}$ ). This procedure is in accordance with the regulations of the Polish Animal Welfare Act. Hippocampi were dissected from 2- to 4-d-old rats, sliced, treated with trypsin, mechanically dissociated and centrifuged twice at $40 \times g$, plated in the Petri dishes, and cultured. Experiments were performed on cells between 10 and $15 \mathrm{~d}$ in culture.

Electrophysiological recordings. Currents were recorded in the wholecell and outside-out mode of the patch-clamp technique, using the EPC-7 amplifier (List Medical, Darmstadt, Germany) at a holding potential $\left(V_{\mathrm{h}}\right)$ of $-70 \mathrm{mV}$. The intrapipette solution contained (in $\mathrm{mM}$ ) 137 $\mathrm{CsCl}, 1 \mathrm{CaCl}_{2}, 2 \mathrm{MgCl}_{2}, 11$ BAPTA, 2 ATP, 10 HEPES, pH 7.2, with $\mathrm{CsOH}$. The composition of the standard external solution was (in mM) $137 \mathrm{NaCl}, 5 \mathrm{KCl}, 2 \mathrm{CaCl}_{2}, 1 \mathrm{MgCl}_{2}, 20$ glucose, $10 \mathrm{HEPES}$, pH 7.2, with $\mathrm{NaOH}$. HEPES was used to buffer the external solutions with $\mathrm{pH}$ in the range 6.8-8.0. For external solutions with $\mathrm{pH}$ between 5.0 and 6.8, MES $\left(\mathrm{C}_{6} \mathrm{H}_{13} \mathrm{NO}_{4} \mathrm{~S}\right)$ was used at concentration of $15 \mathrm{~mm}$. In experiments performed by using external solutions with $\mathrm{pH}$ higher than 8.0 (buffered with $20 \mathrm{~mm}$ TRIS), the conditions of cells quickly deteriorated, giving rise to a progressive increase in leakage current and eventually to loss of patch. For this reason the upper limit of $\mathrm{pH}$ considered in the present study was set at 8.0. Acidic $\mathrm{pH}$, even at values as low as $5.0-6.0$, was much less harmful to the cells than basic ones above 8.0. Recordings at acidic $\mathrm{pH}$ (not lower than 6.0) showed a better stability even than in control conditions ( $\mathrm{pH}$ 7.2). The whole-cell recordings for the considered $\mathrm{pH}$ range were characterized by good stability for up to $30 \mathrm{~min}$ (records in which $>10 \%$ rundown occurred were excluded from the analysis). To reduce the impact of rundown further, we recorded mIPSCs in $5 \mathrm{~min}$ sweeps, alternating controls ( $\mathrm{pH} 7.2)$ with recordings at various $\mathrm{pH}$ values. Within 5-10 min recordings the rundown was negligible.

The characteristics of the time course (e.g., 10-90\% rise time, time constants of desensitization and deactivation. . . ) of current responses to rapid GABA applications showed little cell-to-cell variability, so the values of these parameters estimated from different cells were pooled. The analysis of proton effect on current amplitudes required a comparison of recordings made on the same patch (see Fig. 2). Stable recordings ( $<10 \%$ of rundown) were available for $\sim 10-20 \mathrm{~min}$. Because current responses were recorded every 1-2 min, the impact of rundown was small. Controls and recordings at various $\mathrm{pH}$ were alternated. The amount of rundown was estimated from control current amplitudes before and after the test pulse. In the case of detectable rundown, the amplitude of the test current was compared with the average of control amplitudes immediately before and after the test recording. Because the pulses were separated by the same time interval, such a procedure allowed for an interpolation of the control current amplitude at the moment of the test recording. Rundown was faster at basic $\mathrm{pH}$ (up to $10 \%$ rundown within $\sim 10 \mathrm{~min}$ ), but application of the interpolation procedure described above allowed for the comparison of peak currents at various $\mathrm{pH}$ values.

All experiments were performed at room temperature, $22-24^{\circ} \mathrm{C}$. $\mathrm{mIP}$ SCs were recorded in the whole-cell configuration in the presence of tetrodotoxin (TTX; $1 \mu \mathrm{M}$ ) and kynurenic acid ( $1 \mathrm{~mm}$ ). In the whole-cell mode the series resistance $\left(R_{s}\right)$ was in the range $4-8 \mathrm{M} \Omega$, and $50-70 \%$ of $R_{s}$ compensation was accomplished.

The current signals were low-pass filtered at $10 \mathrm{kHz}$ with a Butter- worth filter and sampled at $50-100 \mathrm{kHz}$, using the analog-to-digital converter CED micro1401 (Cambridge Electronic Design, Cambridge, UK), and were stored on the computer hard disk. The acquisition and analysis software were kindly given by Dr. J. Dempster (Strathclyde University, Glasgow, UK).

GABA was applied to excised patches via the ultrafast perfusion system, based on a piezoelectric-driven theta-glass application pipette (Jonas, 1995). The piezoelectric translator was from Physik Instrumente (preloaded HVPZT translator, $80 \mu \mathrm{m}$; Waldbronn, Germany) and the theta-glass tubing from Hilgenberg (Malsfeld, Germany). The open tip recordings of the liquid junction potentials revealed that a complete exchange of solution occurred within $40-60 \mu \mathrm{sec}$. A minimum duration of drug application was $\sim 1 \mathrm{msec}$ (when shorter pulses were applied, oscillations often appeared). At very low GABA concentrations (0.2-5 $\mu \mathrm{M})$ the current responses were too small in excised patches and therefore were recorded in the whole-cell configuration with a multibarrel system RSC-200 (Bio-Logic, Grenoble, France). With the use of this system the exchange of solution surrounding an open tip occurred within $10-20 \mathrm{msec}$ (in the whole-cell mode). To assess the exchange time around a neuron, we have recorded the current responses to high potassium saline and to saturating [GABA] in the whole-cell configuration. In both cases the onset of response was characterized by $10-90 \%$ rise time between 15 and $25 \mathrm{msec}$. Because at these GABA concentrations the rise time was considerably slower than $100 \mathrm{msec}$, such application speed was sufficient to describe the time course of these responses.

Analysis. The decaying phase of the currents was fit with a function in the form:

$$
y(t)=\sum_{i=1}^{n} A_{\mathrm{i}} \exp \left(-t / \tau_{\mathrm{i}}\right)+A_{\mathrm{s}},
$$

where $A_{i}$ is the fraction of respective components, $A_{s}$ is the steady-state current, and $\tau_{\mathrm{i}}$ is the time constant. For normalized currents, $\Sigma A_{i}+A_{s}=$ 1. Deactivation time course was well fit with a sum of two exponentials $(n=2)$ and $A_{s}=0$. The desensitization onset was fit with either one or two exponentials and $A_{s}>0$.

The recovery process in the double-pulse protocol (see Fig. $4 F-I$ ) was estimated by using the following formula:

$$
R=\left(I_{2}-I_{\text {end }}\right) /\left(I_{1}-I_{\text {end }}\right),
$$

where $R$ is the percentage of recovery, $I_{1}$ the first peak amplitude, $I_{\text {end }}$ the current value immediately before the application of the second pulse, and $I_{2}$ the second peak amplitude.

The kinetic modeling was performed with the Bioq software kindly provided by Dr. H. Parnas (Hebrew University, Jerusalem, Israel). The Bioq software converted the kinetic model (see Fig. 6A) into a set of differential equations and solved them numerically assuming, as the initial condition, that at $t=0$ no bound or open receptors were present. Various experimental protocols were investigated by "clamping" the agonist concentration time course in the form of square-like pulses (ultrafast perfusion experiments) or "synaptic GABA application" in the exponential form: $A \cdot \exp (-t / \tau)$, where $A$ is the peak concentration and $\tau$ is the time constant of agonist clearance. The solution of such equations yielded the time courses of occupancies of all of the states included in the model. The fitting algorithm was based on a choice of the entire set of the rate constants that best reproduced the time course of currents recorded in all of the protocols that were used. To this end, changes in respective rate constants were introduced manually, and the parameters describing the time course (10-90\% rise-time, steady-state to peak, time constants of desensitization, deactivation... ) for model predictions and experimental traces were compared.

Data are expressed as the mean \pm SEM. The amplitudes of both synaptic currents (see Fig. 1) and of current responses to rapid GABA applications were measured at various $\mathrm{pH}$, and a comparison was made to the peaks of control currents (at pH 7.2) measured on the same cell or excised patch. Thus for analysis of amplitudes the Student's paired $t$ test was used. For other parameters such as rise time (see Figs. $1 F, 2 F, G$ ), time constants, and respective fractions of slow and fast components of deac- 

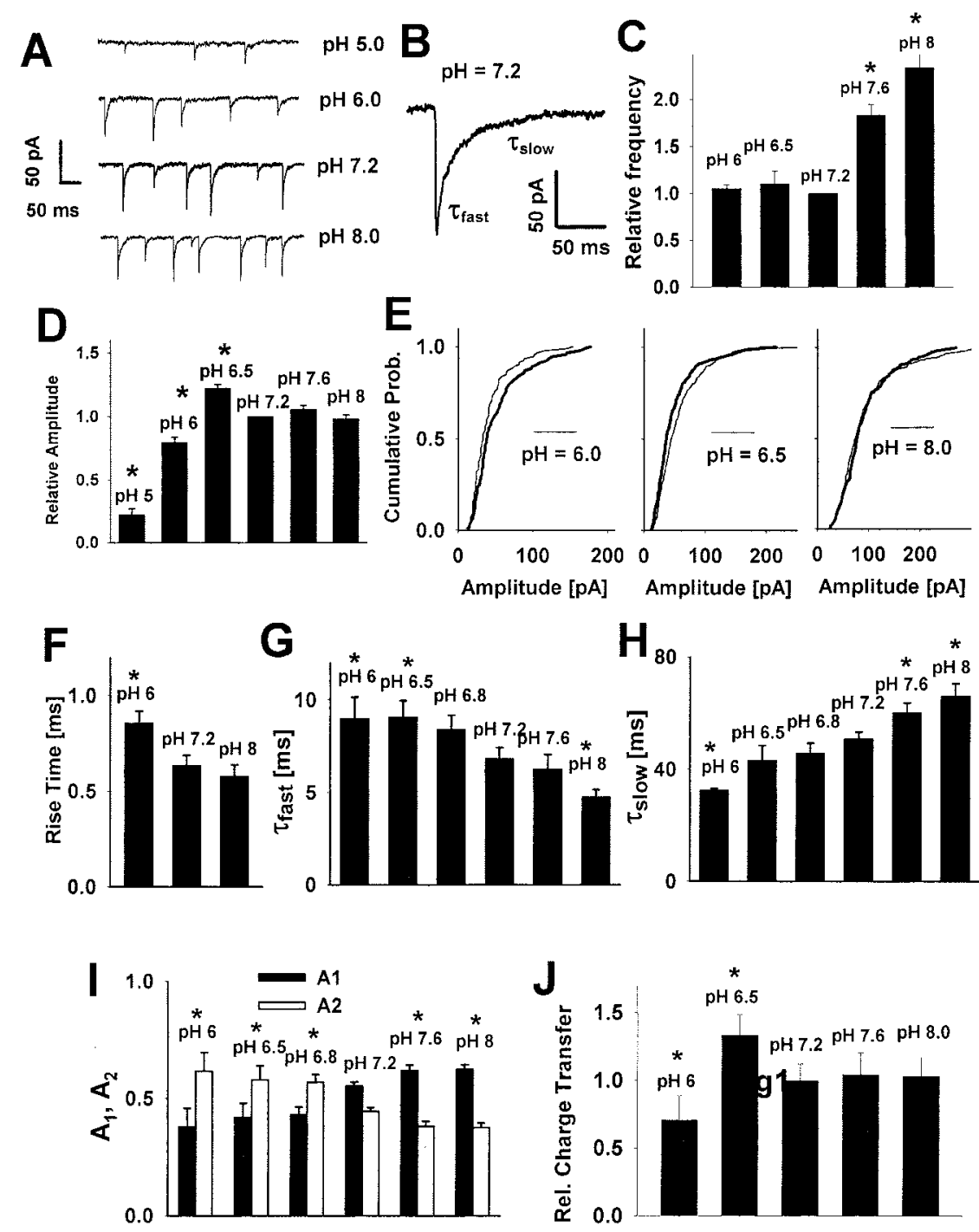

Figure 1. Hydrogen ions affect the amplitudes, frequency, and time course of mIPSCs. A, Examples of mIPSCs recorded at different $\mathrm{pH}$ values (indicated on the right side of the traces) and at holding potential of $-70 \mathrm{mV}$. $B$, Typical averaged mIPSC recorded at $-70 \mathrm{mV}$ and at $\mathrm{pH} 7.2$. C, $\mathrm{pH}$ dependence of $\mathrm{mIPSC}$ frequency. The frequencies are given relative to the control value (at pH 7.2).D,Dependence of mean amplitude of mIPSC on pH. Note that at pH 6.5 the mean amplitude is larger than in the control conditions ( $\mathrm{pH}$ 7.2). E, Typical cumulative histograms for mIPSC amplitudes recorded at $\mathrm{pH}$ values 6.0,6.5, and 8.0. The thick line in each graph represents the cumulative histogram for amplitudes recorded at $\mathrm{pH} 7.2$ on the same cell. F, Averaged rise time of mIPSCs at pH 6.0,7.2, and 8.0. G, H, Averaged values of the fast $\left(\tau_{\text {fast }}\right)$ and slow $\left(\tau_{\text {slow }}\right)$ components of the decaying phase of the mIPSCs, respectively. The values of the rate constants were obtained from the fit of a sum of two exponentials (see Eq. 1). I, Percentages of fast $A_{1}$ (filled bars) and slow $A_{2}$ (open bars) components of the decaying phase of mIPSCs (see Eq. 1). J, pH dependence of charge transfer mediated by averaged mIPSC. The values of charge transfer were calculated relative to the control (pH 7.2) value. In C, $D$ and $F-J$, each mean value was calculated from recordings from at least six cells. Asterisks indicate significant difference with respect to the control values.

tivation (see Figs. 1, 3, 4) the data were pooled, and the Student's unpaired $t$ test was used.

\section{Results}

Changes in extracellular proton concentration affect the mIPSCs

mIPSCs were recorded in the whole-cell configuration at a membrane voltage of $-70 \mathrm{mV}$ (Fig. $1 A, B$ ). The amplitudes of mIPSCs showed large cell-to-cell variability; in control conditions $(\mathrm{pH}$ $7.2)$ the averaged peak value was $43.24 \pm 2.57 \mathrm{pA}(n=39)$. At control and acidic $\mathrm{pH}(6.0-7.2)$ the averaged frequency of mIPSCs showed little variability (at pH 7.2, $1.21 \pm 0.09 \mathrm{~Hz} ; n=$ 18 ), but at lower proton concentrations ( $\mathrm{pH} 7.6$ and 8.0) it was increased significantly (Fig. 1C). The effect of hydrogen ions on mIPSC amplitude was examined within the $\mathrm{pH}$ range $5.0-8.0$, and amplitudes at each $\mathrm{pH}$ were calculated relative to the control value ( $\mathrm{pH} 7.2)$ recorded on the same cell. Strongly acidic $\mathrm{pH}(5.0-6.0)$ caused a pronounced reduction, whereas at basic $\mathrm{pH}$ values the mIPSC amplitude was affected only weakly (Fig. $1 D, E)$. At pH 5.0, in two of six cells that were tested, a complete inhibition of mIPSCs was observed. Interestingly, at pH 6.5 the peak of mIPSCs was increased with respect to control (Fig. $1 D)$. As shown in Figure $1 E$, these effects of hydrogen ions on mIPSC amplitudes are associated with clear shifts in the cumulative amplitude histograms.

The analysis of the time course of the mIPSCs was performed on averaged current traces (Fig. $1 B$ ). In control conditions ( $\mathrm{pH} 7.2$ ) the averaged mIPSC rise time was $0.65 \pm 0.06 \mathrm{msec}(n=9)$. The mIPSC onset phase accelerated with increasing $\mathrm{pH}$ (Fig. $1 F$ ), but this effect was significant $(p<0.05)$ only at strongly acidic $\mathrm{pH}$ values (at pH 6.0, $0.84 \pm 0.07 ; n=6$ ). The decaying phase of mIPSCs was clearly biphasic and at pH 7.2 could be described with a sum of exponentials ( $\tau_{\text {fast }}=6.85 \pm$ $0.59 \mathrm{msec}, A_{1}=0.56 \pm 0.012, \tau_{\text {slow }}=$ $51.08 \pm 2.35 \mathrm{msec}, A_{2}=0.44 \pm 0.12 ; n=$ 26). Increase in $\mathrm{pH}$ affected the decay of the mIPSCs by decreasing the value of rapid time constant $\left(\tau_{\text {fast }}\right.$; Fig. $\left.1 G\right)$ and by increasing the slow one $\left(\tau_{\text {slow }}\right.$; Fig. $\left.1 H\right)$. Moreover, when $\mathrm{pH}$ was increased, the fractions of the fast and slow components $\left(A_{1}\right.$ and $\left.A_{2}\right)$ monotonically increased and decreased, respectively (Fig. 1I). At pH 7.2 the averaged charge transfer mediated by mIPSCs was $1.21 \pm 0.14 \mathrm{pC}(n=9)$, and this parameter showed a $\mathrm{pH}$ dependence (Fig. $1 J)$ that was qualitatively similar to that observed for mIPSC amplitudes (Fig. 1D).

\section{The effect of hydrogen ions on the} kinetics of currents evoked by ultrafast applications of GABA

To describe the effects of hydrogen ions on $\mathrm{GABA}_{\mathrm{A}}$ receptor gating in the time scale corresponding to that of the synaptic events, we studied the current responses to ultrafast GABA applications.

\section{Amplitudes of current responses to saturating GABA} concentrations strongly depend on proton concentration At sufficiently high (saturating) GABA concentrations the binding step becomes much faster than any ligand-independent transition, and both the current amplitude (proportional to the occupancy of open states) and the onset rate reach their maximum values. Pasternack et al. (1996) have reported that acidic pH upregulated the amplitudes of current responses to nearly saturating [GABA] $(500 \mu \mathrm{M})$. However, the perfusion system used by 

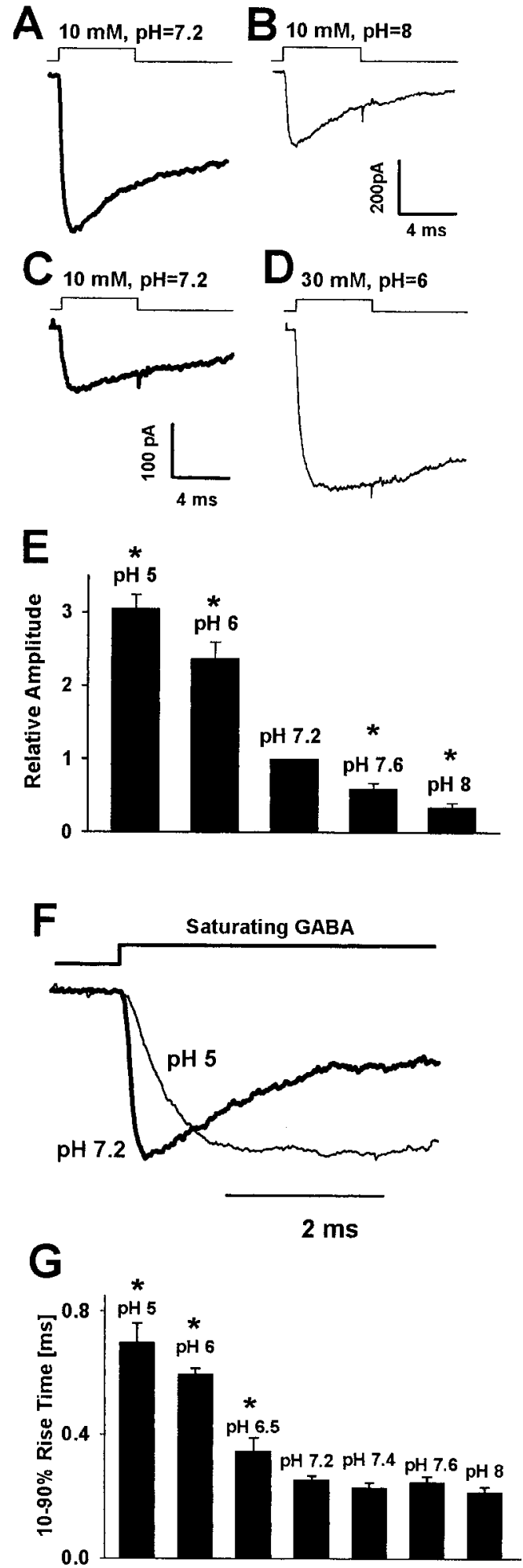

Figure 2. Changes in extracellular proton concentration strongly affect the amplitudes and the rise time of current responses evoked by saturating GABA concentrations. $A, B$, Typical current responses to $10 \mathrm{~mm} G A B A$ recorded from the same patch at $\mathrm{pH} 7.2$ (thick line) and at $\mathrm{pH}$ 8.0 (thin line). C, D, Examples of responses to $10 \mathrm{~mm}$ (at pH 7.2, thick line) and to $30 \mathrm{~mm}$ (at pH 6.0 , thin line) recorded from the same patch. $E$, Dependence of relative current amplitude (divided by the value of amplitude recorded at pH 7.2 from the same cell) on pH. F, Normalized currents recorded at $\mathrm{pH} 5.0$ and 7.2. G, Dependence of averaged $10-90 \%$ rise times of currents on $\mathrm{pH}$ value. The time course of applied GABA is depicted by the inset above the current traces. Each average was calculated for responses recorded from at least 12 patches. Asterisks indicate significant difference with respect to the control values. these authors was relatively slow, and it cannot be excluded that receptors partially predesensitized before reaching the peak. To clarify this issue, we recorded current responses to ultrafast applications of saturating [GABA] $(10-30 \mathrm{~mm})$ at $\mathrm{pH}$ ranging from 5.0 to 8.0. To ensure that the agonist concentration was saturating at each $\mathrm{pH}$ value, we varied [GABA] between 10 and $30 \mathrm{~mm}$. At $\mathrm{pH}$ higher or equal to $7.2,10 \mathrm{~mm}$ was saturating, and at $\mathrm{pH}$ lower than 7.2, $30 \mathrm{~mm}$ was used to ensure the saturating conditions. For instance, at $\mathrm{pH} 5.0$ the $10-90 \%$ rise times of responses to 30 and $10 \mathrm{~mm}$ GABA were $0.69 \pm 0.06 \mathrm{msec}(n=11)$ and $1.22 \pm 0.14 \mathrm{msec}(n=5)$, respectively, indicating that $10 \mathrm{~mm}$ was insufficient to saturate the response at this proton concentration. As recently shown by Mercik et al. (2002), $30 \mathrm{~mm}$ GABA induced a self-block of current responses at $\mathrm{pH}$ 7.2. However, at lower $\mathrm{pH}$ $(6.5,6.0,5.0)$ this effect was not observed (at $30 \mathrm{~mm}$ GABA; data not shown), which is consistent with one of the conclusions of the present work that acidic $\mathrm{pH}$ reduces the affinity of $\mathrm{GABA}_{\mathrm{A}} \mathrm{R}$ (see below). At $\mathrm{pH} 7.2$ the averaged amplitude of currents evoked by $10 \mathrm{~mm}$ GABA was $257.2 \pm 32.4 \mathrm{pA}(n=47)$. As shown in Figure $2 A-E$, the amplitude of these responses showed a strong and monotonic dependence on proton concentration, decreasing approximately onefold per $\mathrm{pH}$ unit. As previously mentioned, this finding is puzzling particularly in the light of the lack of proton effect on both single-channel conductance and frequency (Krishek et al., 2001). Moreover, the effect of proton concentration on amplitudes of mIPSCs was almost opposite (Fig. 1D). Thus to explore the mechanism underlying these effects of hydrogen ions further, we used more experimental protocols.

\section{The rise time kinetics of current responses to saturating GABA is} modulated by protons

The current onset rate was assessed as $10-90 \%$ rise time of current response. As shown in Figure 2, $F$ and $G$, acidification of external solution markedly slowed down the rising phase kinetics, whereas at basic $\mathrm{pH}$ a slight acceleration was present. At first glance, this result could suggest that an increase in proton concentration slows down the transition rate from the bound closed to the bound open state $\left(\beta_{2}\right.$; model in Fig. $\left.6 A\right)$, but it is also possible that the transition to quickly desensitized state could affect the current rise time (see Model simulations).

Effect of proton concentration on the deactivation kinetics After agonist removal the current response does not fall immediately to zero but shows a relaxation defined as the deactivation process that, for $\mathrm{GABA}_{\mathrm{A}} \mathrm{R}$-mediated responses, may exceed hundreds of milliseconds (see Jones and Westbrook, 1995; Mozrzymas et al., 1999). Jones and Westbrook (1995) have demonstrated that the mechanism underlying such slow decaying phase is a slow unbinding rate that favors multiple sojourns in the open and desensitized states. Moreover, because the presence of agonist in the synapse is very short (at most, hundreds of microseconds; Clements, 1996; Mozrzymas et al., 1999), the decaying phase of IPSCs represents mainly the deactivation process. The deactivation kinetics thus may provide important information on proportions among unbinding, opening, and desensitization rates. In control conditions ( $\mathrm{pH} 7.2$ ) the deactivation was clearly bipha$\operatorname{sic}\left(\tau_{\text {fast }}=2.47 \pm 0.17 \mathrm{msec}, A_{1}=0.725 \pm 0.11, \tau_{\text {slow }}=110 \pm 7.5\right.$ msec, $\left.A_{2}=0.275 \pm 0.06 ; n=27\right)$. The fast deactivation component $\left(\tau_{\text {fast }}\right)$ was similar to that found, for example, by Berger et al. [2.2 msec (1998)], Zhu and Vicini [3.6 msec(1997)], and Perrais and Ropert [3.1 msec (1999)] but differed substantially from that reported by, for example, Jones and Westbrook [18 msec (1995)] as well as Banks and Pearce [13.9 msec (2000)]. This diversity may reflect a variety of receptor types and differences in experi- 

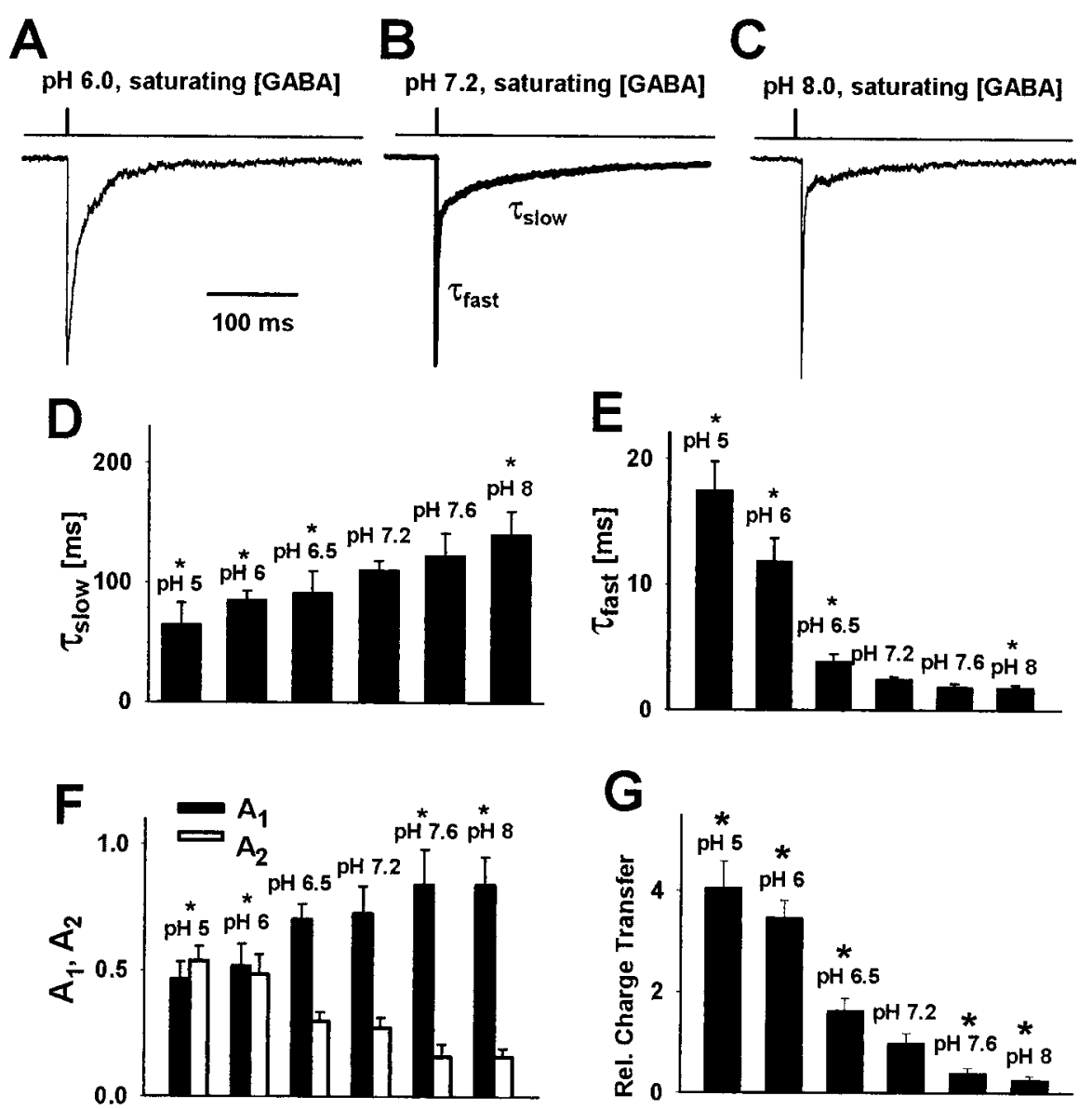

Figure 3. Extracellular proton concentration modulates the deactivation kinetics of current responses elicited by short applications of saturating GABA concentrations. $A-C$, Typical current responses to saturating GABA applied for 2 msec. At pH 6.0 ( $A$ ), 30 mM GABA was used to ensure saturation, whereas at pH 7.2 (B) and pH 8.0 ( $(0) 10 \mathrm{~mm} \mathrm{GABA}$ was applied. The time course of applied GABA is depicted by the insets above the current traces. $D, E$, Averaged values of the fast $\left(\tau_{\text {fast }}\right)$ and slow $\left(\tau_{\text {slow }}\right)$ components of deactivation time course, respectively, at different values of $\mathrm{pH}$. The values of the rate constants were obtained by fitting Equation 1. F, Percentages of fast $A_{1}$ (filled bars) and slow $A_{2}$ (open bars) components of the deactivation process (see Eq. 1). Each average was calculated for responses recorded from at least nine patches. Note that the $\mathrm{pH}$ dependence of deactivation qualitatively reproduces the effects of hydrogen ions on the decaying phase of mIPSCs (see Fig. 2). G, pH dependence of charge transfer mediated by averaged current response to a short pulse of saturating [GABA]. The values of charge transfer were calculated relative to the control ( $\mathrm{pH}$ 7.2) value. Asterisks indicate significant difference with respect to the control values.

mental conditions. The slow time constant $\tau_{\text {slow }}$ was clearly larger than that in the case of mIPSCs (compare Figs. $1 H, 3 D$ ), and this difference may be attributed to different receptor properties (Banks and Pearce, 2000). A markedly faster rapid phase of decay $\left(\tau_{\text {fast }}\right)$ in the case of current responses (Figs. 1G, 3E) is likely to result additionally from a much smaller electrotonic filtering by the excised patch of neuronal membrane than in the case of synaptic current recordings. Similarly to mIPSCs, the slow decay component increased and the fast one decreased with increasing $\mathrm{pH}$ (Fig. 3D,E). Moreover, the fractions of fast and slow time constants increased and decreased, respectively, with $\mathrm{pH}$ (Fig. $3 F)$. At $\mathrm{pH} 7.2$ the averaged charge transfer mediated by current responses to short applications of saturating [GABA] was $8.34 \pm$ $2.4 \mathrm{pC}(n=9)$, and this parameter showed a monotonic decrease at increasing $\mathrm{pH}$ (Fig. $3 G)$.

Hydrogen ions affect the desensitization of $G A B A_{A}$ receptors Long applications of saturating GABA concentration were used to study the kinetics of the desensitization process (Fig. $4 A-E$ ). When 300 msec pulses were applied at pH 7.2, the desensitization onset was clearly biphasic and characterized by the time constants $\left(\tau_{\text {fast }}=2.41 \pm 0.17 \mathrm{msec}, A_{1}=0.76 \pm\right.$ $0.11, \tau_{\text {slow }}=126 \pm 7.5 \mathrm{msec}, A_{2}=0.14 \pm$ $\left.0.04, A_{\mathrm{s}}=0.1 \pm 0.01 ; n=16\right)$. The slow phase of desensitization becomes clearly visible during long applications of agonist $(>100 \mathrm{msec})$, whereas the synaptic clearance, as previously mentioned, is believed to occur within hundreds of microseconds. Moreover, because of faster rate into the rapidly desensitizing state, the role of this conformation in shaping the deactivation kinetics appears to be predominant. This is supported by the proper reproduction of the deactivation time course, using the kinetic model including only the fast desensitizing state (Jones and Westbrook, 1995; Mozrzymas et al., 1999; Barberis et al., 2000) (see also Model simulations). Thus the analysis of the desensitization onset has been limited to the fast component that at $50 \mathrm{msec}$ pulse duration was predominant (at $\mathrm{pH} \mathrm{7.2,} \tau_{\text {fast }}=2.78 \pm$ $0.17 \mathrm{msec}, A_{1}=0.8085 \pm 0.11, A_{\mathrm{s}}=$ $0.1915 \pm 0.02 ; n=27)$. Increase in $\mathrm{pH}$ caused a marked acceleration of the desensitization onset (Fig. 4A-D) and reduction of the steady-state to peak ratio (Fig. $4 A-$ $C, E)$. These effects were associated with a decrease in amplitude as presented in Figure 2A-E. The desensitization onset at acidic $\mathrm{pH}$ was studied by the application of long pulses of $30 \mathrm{~mm}$ GABA (instead of 10 $\mathrm{mM})$ to ensure the saturation conditions.

Pairs of short $(2-3 \mathrm{msec})$ pulses of saturating [GABA] separated by a variable gap were used to assess the recovery of the second pulse amplitude. Basic $\mathrm{pH}$ slowed down, whereas acidic $\mathrm{pH}$ accelerated the recovery process (Fig. $4 F-I$ ). This effect potentially could involve at least three factors: increase in the desensitization rate $\left(d_{2}\right)$, decrease in resensitization rate $\left(r_{2}\right)$, and decrease in the unbinding rate $\left(k_{\text {off }}\right)$ when proton concentration is decreased in the extracellular medium. The effect of $\mathrm{pH}$ on these processes will be discussed in detail in Model simulations.

\section{Hydrogen ions modulate the binding rate of $G A B A$ to the binding site on $G A B A_{A}$ receptor}

At GABA concentrations below saturating ones, the activation of $\mathrm{GABA}_{\mathrm{A}}$ receptor slows down in a dose-dependent manner. This reflects the fact that, for nonsaturating [GABA], activation kinetics of $\mathrm{GABA}_{\mathrm{A}} \mathrm{R}$ depends on GABA binding rate. Thus the analysis of the onset rate of current responses to nonsaturating GABA concentrations may provide us with crucial information on $k_{\mathrm{on}}$ rate constant. The rate of binding is assumed to be proportional to GABA concentration $\left(\sim k_{\text {on }} \cdot[\mathrm{GABA}]\right.$, where $k_{\text {on }}$ is the binding rate constant), and therefore the velocity of binding process can be regulated by setting appropriate GABA concentration. To check for the effect of protons on the binding rate, we recorded current responses to nonsaturating [GABA] (Fig. 5). As shown in Figure $5 A-C$, basic $\mathrm{pH}$ clearly accelerated whereas acidic $\mathrm{pH}$ slowed down the current onset rate. The effect of acidic $\mathrm{pH}$ was 

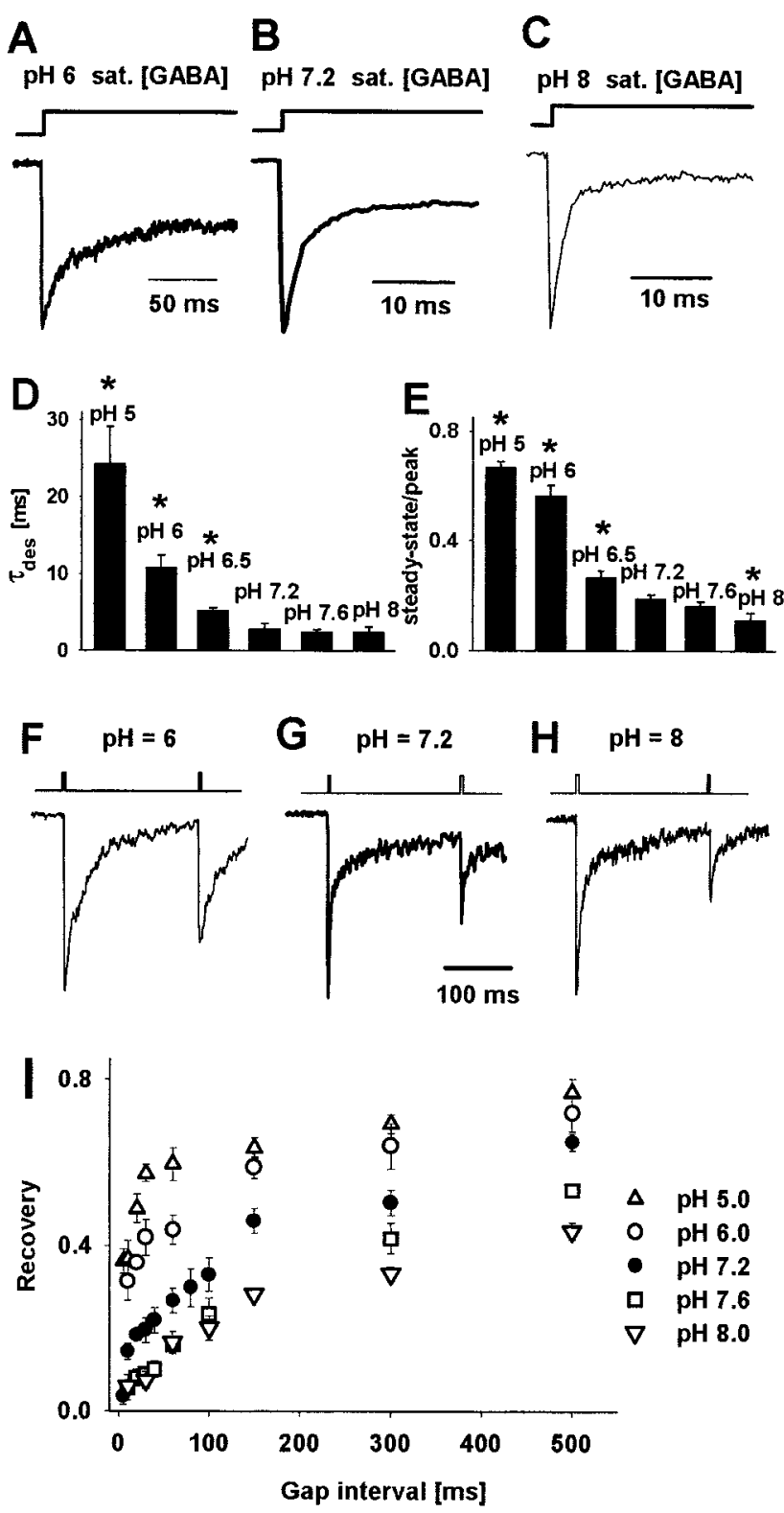

Figure 4. Decrease in pH strongly affects the desensitization process and the recovery of response to the second pulse in the double-pulse experiment. $A-C$, Typical normalized current responses evoked by long pulses of saturating GABA concentrations applied to the same cell. $D$, $E$, $\mathrm{pH}$ dependence of averaged values of the time constant of desensitization onset and steadystate to peak ratio, respectively. The values of parameters presented in $D$ and $E$ were obtained by fitting a sum of one exponential and a constant value to the decaying phase of the current response (Eq. 1). Asterisks in $D$ and $E$ indicate significant difference with respect to the control values. $\mathrm{F}-\mathrm{H}$, Typical current responses to pairs of short pulses (2 msec) of saturating GABA concentrations applied to the same cell. Insets above the current traces indicate the time course of applied agonist. $I$, Dependence of recovery on time duration of gap interval between pulses at different $\mathrm{pH}$ values. The value of the recovery parameter was calculated by using Equation 3 . The values of recovery parameter recorded at $\mathrm{pH}$ values indicated in the graph were significantly different from those measured in control conditions $(\mathrm{pH}=7.2)$ for any considered gap interval longer than $5 \mathrm{msec}$. At pH $6.0(A, F) 30 \mathrm{~mm}$ GABA was used to ensure saturation, whereas at $\mathrm{pH}$ $7.2(B, G)$ and $\mathrm{pH} 8.0(C, H) 10 \mathrm{~mm} G A B A$ was applied. Each average was calculated for responses recorded from at least nine patches.

particularly strong; whereas at $\mathrm{pH} 7.2$ the $10-90 \%$ rise time of current response to $300 \mu \mathrm{M}$ GABA was $1.03 \pm 0.05 \mathrm{msec}(n=$ $20)$, at $\mathrm{pH} 6.0$ and $\mathrm{pH} 5.0$ it was $3.08 \pm 0.54 \mathrm{msec}(n=16)$ and $5.71 \pm 0.87 \mathrm{msec}(n=8)$, respectively. The rise time of currents evoked by $100 \mu \mathrm{M}$ GABA at $\mathrm{pH} 7.2$ was $1.78 \pm 0.2 \mathrm{msec}(n=16)$, and its $\mathrm{pH}$ dependence was qualitatively similar as in the case of currents evoked by $300 \mu \mathrm{M}$ GABA (Fig. 5C). Although the rise time of current responses potentially can be shaped by the desensitization process also, in the range of [GABA] 100-300 $\mu \mathrm{M}$ such strong hydrogen ion effect is unlikely to be predominant because of a modification of desensitization (see also Model simulations).

The effect of proton concentration on the amplitudes of currents evoked by 100 and $300 \mu \mathrm{M}$ GABA was qualitatively similar to that observed for saturating [GABA] (Fig. 2A-E). At 100-300 $\mu \mathrm{M}$ GABA most of receptors reach the fully bound state, $A_{2} R$; therefore, similarly as for responses to saturating [GABA], the peak occupancy of the open state $A_{2} R^{\star}$ depends mainly on the balance between the opening $\beta_{2}$ and desensitization rate $d_{2}$ (see Model simulations below). However, at very low [GABA], binding is expected to be critical for recruitment of receptors into the open state; therefore, the up/downregulation of the binding rate $k_{\text {on }}$ by basic/acidic $\mathrm{pH}$ would be expected to produce an increase/ decrease in amplitude. To test this hypothesis, we recorded current responses to $0.2,1$, and $5 \mu \mathrm{M}$ GABA in control conditions ( $\mathrm{pH} 7.2$ ) as well as at $\mathrm{pH} 6.0$ and $\mathrm{pH}$ 8.0. As explained in Materials and Methods, these experiments were performed in the wholecell configuration because at such low [GABA] the currents in excised patches were too small. At pH 6.0 the responses to $0.2 \mu \mathrm{M}$ GABA were at the baseline noise level, but at higher $\mathrm{pH}$ clear current responses appeared and an increase in amplitude with decreasing proton concentration was evident (Fig. 5D; at pH 7.2, $54 \pm 18 \mathrm{pA} ; n=8)$. Concentration of $1 \mu \mathrm{M}$ GABA was sufficient to evoke detectable response at $\mathrm{pH} 6.0$, and again the currents clearly increased with pH (Fig. 5D, E; at pH 7.2, $244 \pm 27 \mathrm{pA} ; n=$ 7). For responses evoked by $5 \mu \mathrm{M}$ GABA, acidic pH clearly de-

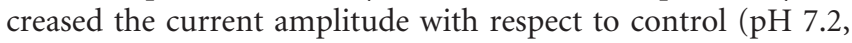
$1108 \pm 68 \mathrm{pA} ; n=9$ ), whereas at basic $\mathrm{pH}$ the amplitude was comparable to that in control conditions (Fig. $5 D, E$ ). For responses elicited by $1-5 \mu \mathrm{M}$ GABA (at $0.2 \mu \mathrm{M}$ GABA the signal-tonoise ratio was insufficient to assess the rise time reliably), the rising phase of current accelerated with $\mathrm{pH}$ (Fig. $5 F$ ). These data further indicate that the binding rate is accelerated with decreasing proton concentration. Our results on current responses to very low [GABA] are qualitatively compatible with observations of Pasternack et al. (1996), who reported that increasing pH enhanced the amplitudes of currents evoked by $5 \mu \mathrm{M}$ GABA in acutely isolated rat pyramidal neurons.

\section{Model simulations}

To provide a better quantitative description of proton effect on $\mathrm{GABA}_{\mathrm{A}}$ receptor gating, we used simulations based on the Jones and Westbrook model (1995) (Fig. 6A). This scheme have been demonstrated to fulfill the criteria for a minimum requirement model, allowing us to reproduce the basic kinetic properties of $\mathrm{GABA}_{\mathrm{A}}$ receptors properly, such as the presence of two binding sites, saturation of onset rate at high [GABA], desensitization onset, and slow deactivation because of functional coupling between slow unbinding and desensitization (Jones and Westbrook, 1995; Jones et al., 1998; Mozrzymas et al., 1999; Barberis et al., 2000).

Simulations of current responses to ultrafast GABA applications The analysis of the current responses to ultrafast GABA applications provided important information on possible mechanisms underlying the effect of hydrogen ions on $\mathrm{GABA}_{\mathrm{A}}$ receptor gating. However, because the occupancy of any conformation depends on all of the transition rates and occupancies of all other states, it is difficult to assess any selected rate constant based on 

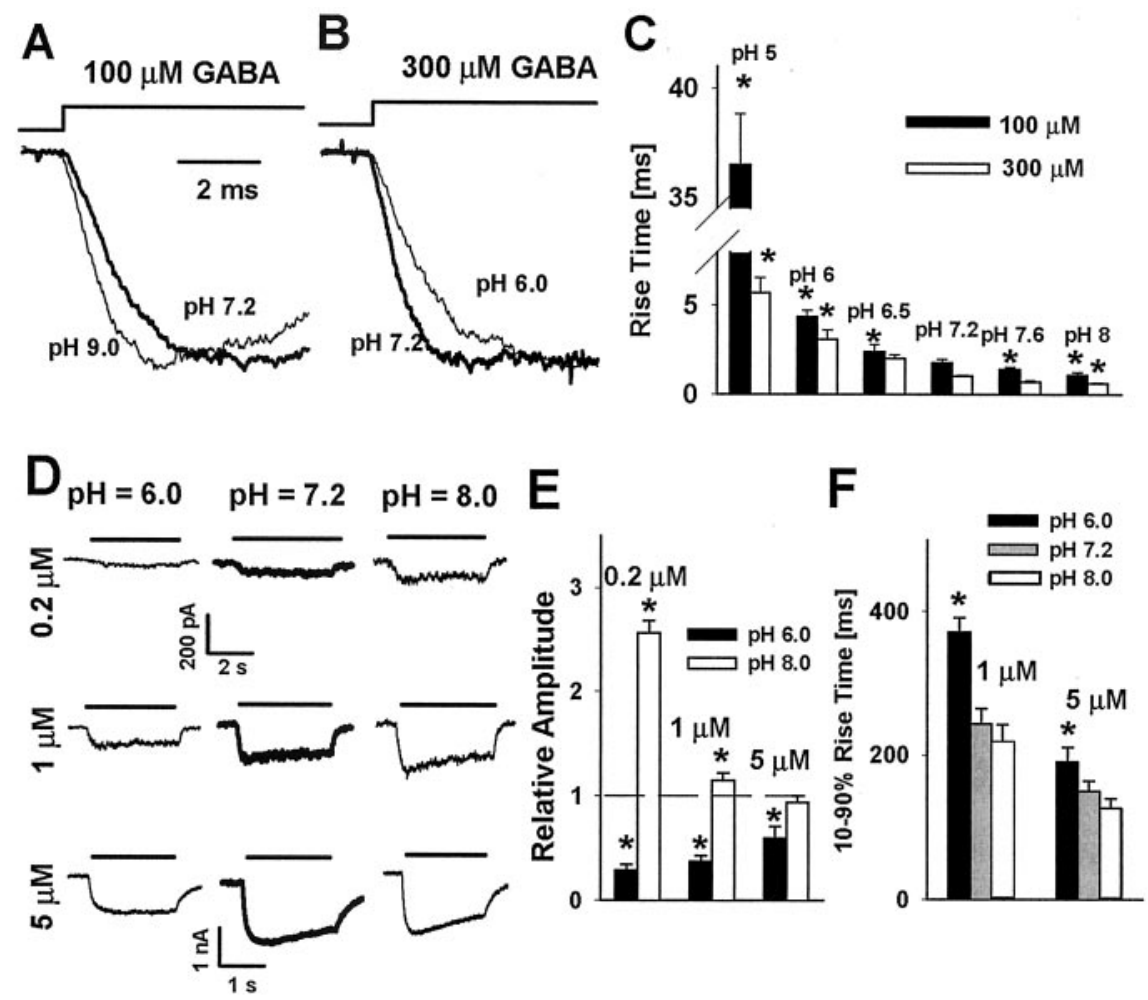

Figure 5. Hydrogen ions affect the time course of current responses to nonsaturating GABA concentrations. $A$, Typical normalized current responses to $100 \mu \mathrm{M}$ GABA in control conditions (pH 7.2, thick line) and at basic pH 8.0 (thin line). B, Typical normalized responses to $300 \mu \mathrm{m}$ GABA in control conditions (pH 7.2, thick line) and at basic pH 8.0 (thin line). C, pH dependence of averaged $10-90 \%$ rise times of current responses to $100 \mu \mathrm{m}$ (filled bars) and $300 \mu \mathrm{m}$ (open bars) GABA. D, Typical current responses to $0.2,1$, and $5 \mu \mathrm{m} \mathrm{GABA}$ at pH 6.0 (left), pH 7.2 (middle, thick lines), and pH 8.0 (right). Insets above the current traces indicate the application time of the agonist. $E$, Relative amplitudes (normalized to the amplitudes of currents recorded from the same cell at pH 7.2) of currents evoked by $0.2,1$, and $5 \mu \mathrm{M}$ at $\mathrm{pH} 6.0$ (filled bars) and at $\mathrm{pH} 8.0$ (open bars). F, pH dependence of $10-90 \%$ rise times of currents elicited by 1 and $5 \mu \mathrm{m}$ GABA. Each average was calculated for responses recorded from at least eight patches. Asterisks indicate significant difference with respect to the control values.

the use of any single experimental protocol. Therefore, the optimization procedure was performed until the entire set of the rate constants allowed us to reproduce optimally the time course of currents recorded with all of the protocols that were used (Figs. 2-5). The most important experimental observations were that an increase in $\mathrm{pH}$ caused (1) a decrease in amplitude of currents evoked by saturating [GABA] (Fig. 2A-E), whereas the opposite effect was observed at low [GABA] (Fig. 5D,E), (2) an increase in the rate and extent of desensitization (Fig. 4A-E), and (3) an increase in the onset rate of responses evoked by nonsaturating [GABA] (Fig. 5).

In general, the effect of proton concentration not only might affect the rate constants but also induce a rearrangement of the kinetic scheme. In such a case one would expect that macroscopic characteristics of currents (e.g., desensitization or rise time) would show mixed kinetics described by time constants typical for control ( $\mathrm{pH}$ 7.2) and other modes with weights depending on $\mathrm{pH}$. However, the analysis of the current rising phase, desensitization, and deactivation indicated gradual proton-induced changes. Similarly, a change in receptor properties in a discrete manner (mode switch) would be expected to increase the number of macroscopic kinetic components that, as mentioned, was not observed. On the other hand, it cannot be excluded that progressive protonation/deprotonation of $\mathrm{GABA}_{\mathrm{A}} \mathrm{R}$ macromolecules induces a number of mode-like changes. Such multimodal transitions when a large (and heterogeneous) channel population is observed could give rise to a progressive, gradual change in current kinetics. This suggests that proton-induced mode switching would rely on modification of the $\mathrm{GABA}_{\mathrm{A}} \mathrm{R}$ microscopic gating by hydrogen ions.

To quantify our experimental observations, we have made an attempt to reproduce the proton-induced effects by gradual variations of the respective rate constants. Our experiments suggested that a rise in $\mathrm{pH}$ could induce an increase in $d_{2}$, $\beta_{2}$, and $k_{\text {on }}$ and a decrease in $r_{2}$. Initially, for control conditions the set of the rate constants assessed by Barberis et al. (2000) was used. As expected, a reduction of $d_{2}$ produced a slower desensitization onset and an increase in amplitude of currents evoked by saturating [GABA]. However, when $d_{2}$ was reduced, the current amplitude could be enhanced by at most $\left[d_{2}\right]$ $\left(\beta_{2}+d_{2}\right)$, i.e., for $\beta_{2}=8 \mathrm{msec}^{-1}$ and $d_{2}=$ $1.5 \mathrm{msec}^{-1}$ (Barberis et al., 2000)] by $\sim 16 \%$, which is much less than in the experiment (Fig. $2 A-E$ ). A similar difficulty was encountered when the rate constants from other studies were considered (Jones and Westbrook, 1995; Maric et al., 1999; Banks and Pearce, 2000; Burkat et al., 2001) because all of them postulate that the opening $\beta_{2}$ is much faster than the desensitization rate $d_{2}$. However, when (for $\mathrm{pH} 7.2) \beta_{2}=3 \mathrm{msec}^{-1}$ and $d_{2}=12$ $\mathrm{msec}^{-1}$ are set, a decrease or increase in $d_{2}$ was sufficient to reproduce the $\mathrm{pH}$ dependence of current amplitudes properly (compare Figs. 6B-E, 2A-E). Such qualitative change in $d_{2}$ and $\beta_{2}$ with respect to the previous models also made it necessary to reassess other rate constants to mimic the currents recorded with other protocols (Figs. 3, 4). In control conditions an optimal reproduction of deactivation and desensitization kinetics required setting $k_{\text {off }}=1 \mathrm{msec}^{-1}$ and $r_{2}=0.07$ msec $^{-1}$. The rate constants $\left(\alpha_{1}, \beta_{1}, d_{1}, r_{1}\right)$ describing transitions for the singly bound open $\left(A R^{\star}\right)$ and desensitized $(A D)$ states were estimated for the same experimental model in a separate study (Mozrzymas et al., 2003). In model simulations of current responses to ultrafast GABA applications (Figs. 2-5) the occupancy of singly bound states was negligible, and we made a simplifying assumption that the kinetics of these states does not depend on proton concentration.

As shown in Figure 6, the sets of the rate constants (Table 1) allowed us to reproduce properly the $\mathrm{pH}$ dependence of currents recorded with various experimental protocols. The major changes were required in desensitization $\left(d_{2}\right)$ and binding $\left(k_{\text {on }}\right)$, and small modifications were made in unbinding ( $\left.k_{\text {off }}\right)$ and resensitization rates $\left(r_{2}\right)$. In addition to binding and desensitization rates, the closing rate $\alpha_{2}$ also had to be altered to reproduce strong $\mathrm{pH}$ dependencies of rapid components of both deactivation (Fig. 3 ) and desensitization (compare Figs. 4, 6F-J). These modifications allowed us to reproduce the $\mathrm{pH}$-induced changes in amplitudes (compare Figs. 6B-E, 2E), deactivation kinetics (compare Figs. $6 F-H, 3$ ), rate and extent of desensitization (compare Figs. $6 J, 4 A-E)$, recovery in the paired pulse protocol (compare Figs. 
$6 K, 4 F-I)$, and rising phase of currents elicited by low [GABA] (compare Figs. $6 \mathrm{~L}$, $5 A-C)$. The recovery process in the double-pulse experiments (Fig. $4 F-I$ ) is a complex phenomenon that may depend on resensitization $r_{2}$, unbinding $k_{\text {off }}$, desensitization $d_{2}$, and opening/closing rates $\alpha_{2} / \beta_{2}$. Our model simulations indicate that the observed $\mathrm{pH}$ dependence of recovery in this protocol results mainly from a decrease in the desensitization rate $d_{2}$ and, to a much smaller extent, from an increase in resensitization $r_{2}$ (Fig. $6 K$, Table 1 ). The present analysis provided evidence for a somehow surprising conclusion that the fastest ligandindependent process in the $\mathrm{GABA}_{\mathrm{A}}$ receptor gating scheme is not the opening (as assumed in most of models) but desensitization.

The analysis of the rise time kinetics of current responses to saturating [GABA] revealed that acidic $\mathrm{pH}$ slows down the rising phase, whereas basic $\mathrm{pH}$ had only a slight effect (Fig. 2F,G). A slower current onset at acidic $\mathrm{pH}$ could suggest a reduction of the transition rate from the bound closed to the bound open state $\left(\beta_{2}\right)$. However, a direct association of a slower rise time with a decrease in $\beta_{2}$ would be correct only in the case in which the opening $\left(\beta_{2}\right)$ would be much faster than the desensitization rate $\left(d_{2}\right)$, which, according to the results presented above, seems not to be the case. Moreover, for the bifurcating reactions (Eq. 3; because $d_{2} \gg r_{2}$ and $\beta_{2} \gg$ $\alpha_{2}$, this scheme is expected to give a good approximation for the initial phase of the current onset for saturating [GABA]) both the onset of current response (occupancy of $\left.A R^{\star}\right)$ and the entry into the desensitized state $(A D)$ proceed with the time constant $\tau=1 /(\beta+d)$ :

$$
\mathrm{AD} \stackrel{d}{\leftarrow} \mathrm{AR} \stackrel{\beta}{\rightarrow} \mathrm{AR}^{\star}
$$

Thus for $d_{2} \gg r_{2}$ the rising phase kinetics is shaped predominantly by the desensitization rate $d_{2}$ (not by $\beta_{2}$ ), and a decrease in $d_{2}$ (at acidic $\mathrm{pH}$ ) is expected to slow down the rising phase of currents (Fig. 6I) similar to what was observed in our experiments (Fig. $2 F, G)$. Basic $\mathrm{pH}$ had only a slight effect on the onset rate of currents evoked by saturating [GABA] (Fig. 2F,G), whereas the model simulations predict a more pronounced acceleration of the current onset (Fig. 6I). This difference results most likely from limits in the velocity of drug application with our perfusion system.

In the light of investigations based on an analysis of Equation 3, the $\mathrm{pH}$-induced alterations in the rise time of currents elicited by nonsaturating GABA concentra-
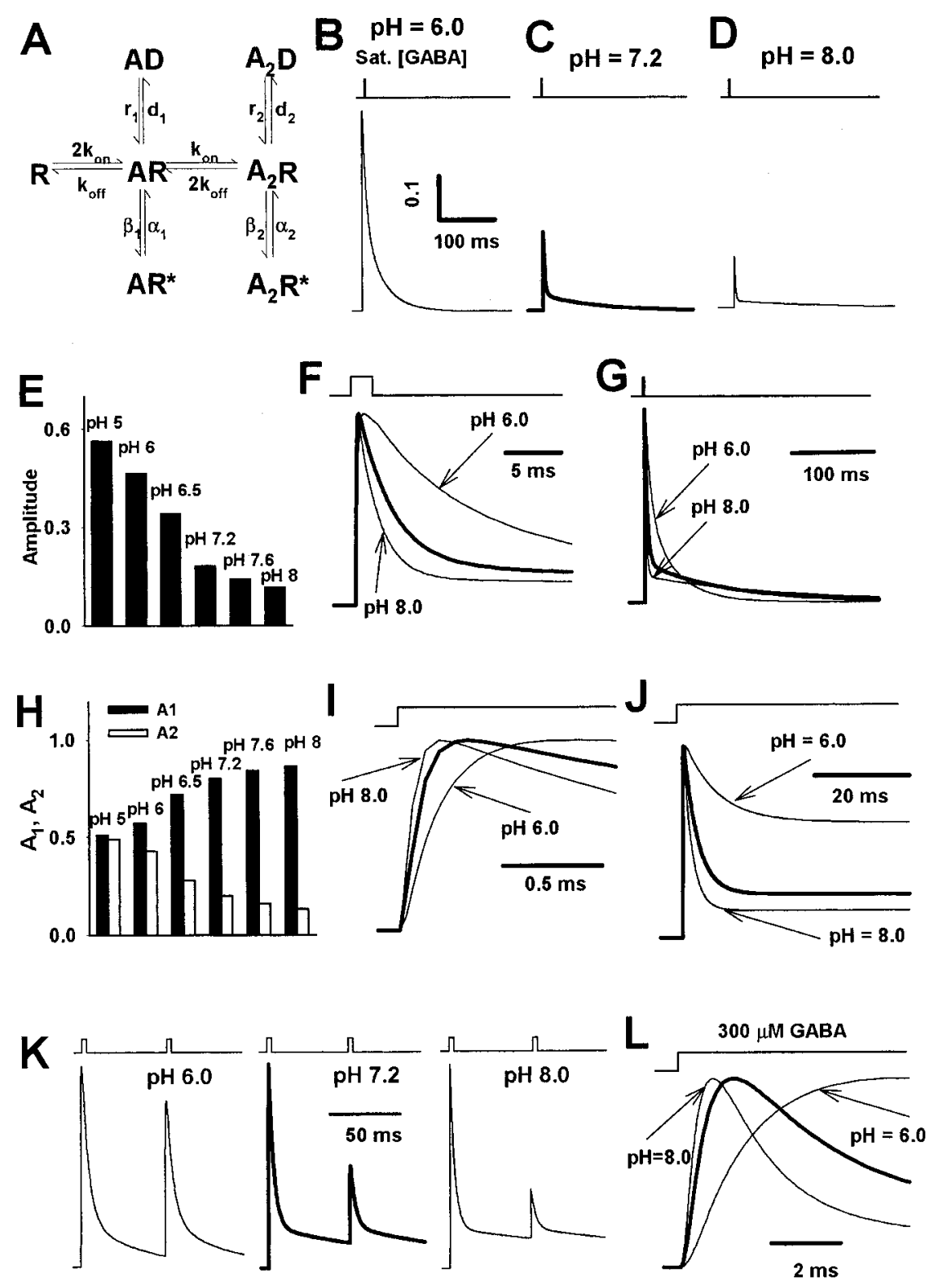

Figure 6. Simulations of current responses elicited by ultrafast GABA applications. The traces represent the total occupancy of open states $\left(A R^{*}\right.$ and $\left.A_{2} R^{*}\right)$. A, Jones and Westbrook's model (1995). $B-D$, Simulated current responses to brief ( $2 \mathrm{msec}$ ) applications of saturating GABA concentrations for the rate constants optimized to reproduce the $G A B A_{A}$ receptor gating at $\mathrm{pH}$ values of $6.0,7.2$, and 8.0 , respectively (see Table 1). $E$, $\mathrm{pH}$ dependence of amplitudes of simulated current responses to saturating GABA concentrations (compare with Fig. 2). F, G, Time courses of simulated deactivation phases of currents evoked by saturating GABA concentrations at pH 6.0,7.2 (thick line), and 8.0. In $F$, a strong proton effect on the fast deactivation component and in $G$ (expanded time scale) on the slow component is seen (compare with Fig. 3 ). $H$, pH dependence of percentages of fast component ( $A_{1}$, filled bars) and of slow component $\left(A_{2}\right.$, open bars). The simulated $\mathrm{pH}$ effect of proton concentration on the deactivation kinetics qualitatively reproduces the experimental observations on mIPSCs (see Fig. 1) and on current responses to exogenous GABA applications (see Fig. 3). I, Simulation of pH effect on the rising phase of normalized currents elicited by saturating GABA concentrations. Note that acidic $\mathrm{pH}$ slows down and basic $\mathrm{pH}$ accelerates the current onset with respect to the control current (pH 7.2, thick line). This qualitatively reproduces the experimental data (see Fig. 2). J, Simulation of the effect of hydrogen ions on the kinetics of the desensitization onset. Normalized responses are shown for pH 6.0,7.2 (thick line), and 8.0. Simulations well reproduce the theory that a decrease in proton concentration accelerates the time constant of desensitization onset and reduces the steadystate to peak ratio (compare with Fig. 4). K, Simulation of current responses evoked by pairs of short pulses. Slower recovery of the second pulse results mainly from an increase in the rate of entry $\left(d_{2}\right)$ into desensitized state at decreasing proton concentration. $L$, Simulation $\mathrm{pH}$ dependence of the rising phase of currents evoked by a nonsaturating GABA concentration $(300 \mu \mathrm{M}$ ). Normalized traces are shown for pH 6.0, 7.2 (thick line), and 8.0 (compare with Fig. 5). In graphs shown in $B-D, F, G, I-L$, the insets above the traces represent the time course of agonist applied at a saturating concentration. 
Table 1. Values of rate constants optimized to reproduce the time course of current responses to rapid GABA applications at different $\mathrm{pH}$

\begin{tabular}{lllllll}
\hline Parameter & $\mathrm{pH} 5.0$ & $\mathrm{pH} 6.0$ & $\mathrm{pH} 6.5$ & $\mathrm{pH7.2}$ & $\mathrm{pH7.6}$ & $\mathrm{pH} \mathrm{8.0}$ \\
\hline$k_{\text {on }} / \mathrm{ms}^{-1} \mathrm{~mm}^{-1}$ & 1.25 & 2.5 & 4.5 & 6.0 & 7.5 & 9.0 \\
$k_{\text {off }} / \mathrm{msec}^{-1}$ & 1.05 & 1.04 & 1.025 & 1.0 & 0.95 & 0.9 \\
$\beta_{1}^{\prime} / \mathrm{msec}^{-1}$ & 0.15 & 0.15 & 0.15 & 0.15 & 0.15 & 0.15 \\
$\alpha_{1} / \mathrm{msec}^{-1}$ & 1.5 & 1.5 & 1.5 & 1.5 & 1.5 & 1.5 \\
$d_{1} / \mathrm{msec}^{-1}$ & 0.045 & 0.045 & 0.045 & 0.045 & 0.045 & 0.045 \\
$r_{1} / \mathrm{msec}^{-1}$ & 0.014 & 0.014 & 0.014 & 0.014 & 0.014 & 0.014 \\
$\beta_{2} / \mathrm{msec}^{-1}$ & 3.0 & 3.0 & 3.0 & 3.0 & 3.0 & 3.0 \\
$\alpha_{2} / \mathrm{msec}^{-1}$ & 0.18 & 0.2 & 0.28 & 0.4 & 0.5 & 0.6 \\
$d_{2} / \mathrm{msec}^{-1}$ & 2.0 & 3.0 & 5.0 & 12.0 & 16.0 & 20.0 \\
$r_{2} / \mathrm{msec}^{-1}$ & 0.08 & 0.078 & 0.07 & 0.07 & 0.07 & 0.07 \\
\hline
\end{tabular}

tions (100-300 $\mu \mathrm{M}$; Fig. 5A-C) could be caused by changes in desensitization kinetics. However, because binding at this [GABA] is considerably slower than both desensitization $\left(d_{2}\right)$ and opening $\left(\beta_{2}\right)$, the kinetics of receptor activation at these GABA concentrations is shaped predominantly by the binding rate.

The experiments in which currents were evoked by very low GABA concentrations (Fig. 5D-F) provided further indication that the binding rate is upregulated by decreasing concentrations of hydrogen ions. At these concentrations only a minority of receptors reaches the fully bound state (especially at 0.2 and $1 \mu \mathrm{M}$ GABA); therefore, the current amplitude is expected to depend on the binding rate. The model simulations well reproduce the experimental findings (for $0.2 \mu \mathrm{M}$ GABA, the occupancies of open state were $0.00011,0.00019$, and 0.00035 at pH $6.0,7.2$, and 8.0, respectively; for $1 \mu \mathrm{M}$ GABA the amplitudes were 0.00061 , 0.0013 , and 0.0021 at $\mathrm{pH} 6.0,7.2$, and 8.0, respectively). Thus our analysis provides a simple explanation for apparently opposite effect of hydrogen ions on amplitudes of responses evoked by very low and saturating [GABA]. At very low agonist concentrations the upregulation of the affinity increases the chance for the receptor to activate, whereas at high [GABA] (at which binding is close to being complete) the current amplitude is set by the balance between entrance into the open $\left(A_{2} R^{\star}\right)$ and desensitized state $\left(A_{2} D\right)$. It is expected that at sufficiently high [GABA] an enhanced recruitment into the bound states caused by an increase in $k_{\text {on }}$ at basic $\mathrm{pH}$ will be counterbalanced by an increased entrance into the desensitized state. Such a trend is reflected by the observation that the current amplitudes evoked by $5 \mu \mathrm{M}$ GABA are comparable in control conditions ( $\mathrm{pH}$ 7.2) and at basic pH 8 (Fig. $5 D, E$ ), whereas, for example, at 100 or $300 \mu \mathrm{M}$ GABA the basic $\mathrm{pH}$ strongly reduces current amplitude.

\section{Simulation of proton effects on synaptic currents}

The model simulations of current responses evoked by ultrafast agonist applications provided key information on the effect of hydrogen ions on the $\mathrm{GABA}_{\mathrm{A}}$ receptors. However, although protons exert a similar effect on decaying phases of IPSCs and current responses (Figs. 1, 3), there is a striking disagreement in the effect on the amplitudes of these currents (compare Figs. $1 D$, $2 E)$. A possible explanation for this discrepancy is that the conditions of receptor activation are different in the two situations. Indeed, it has been demonstrated that the differences between synaptic agonist transient (very fast exponential-like decay) and that applied with ultrafast perfusion (square-like) may give rise to different drug effects on mIPSCs and on current responses to rapid GABA applications (Mozrzymas et al., 1999; Barberis et al., 2000). To elucidate to what extent such difference in the agonist waveform could account for different effects of protons on these currents, we used model simulations (with models described in
Fig. $6 A$, Table 1 ) in which synaptic agonist transient was modeled as an exponentially decaying function: $A \cdot \exp (-t / \tau)$, where $A$ is the peak value and $\tau$ is the time constant of the agonist clearance. $\tau$ was varied between 50 and $1000 \mu \mathrm{sec}$, and $A$ was considered in the range between 1 and $5 \mathrm{~mm}$. In Figure $7 A$, simulated current responses to such "synaptic" GABA applications are shown for various $\mathrm{pH}$ and for $A=1.5 \mathrm{~mm}$ and $\tau=125 \mu \mathrm{sec}$. These synaptic current responses well reproduced the observation that, when proton concentration is increased, the fast component of the decaying phase $\left(\tau_{\text {fast }}\right)$ decreased and the slow one $\left(\tau_{\text {slow }}\right)$ increased (compare Figs. $\left.7 B, C, 1 G, H\right)$. The $\chi^{2}$ statistics were used to select the values of $A$ and $\tau$ that best reproduced the $\mathrm{pH}$ dependence of the mIPSC amplitudes (Fig. $7 D, E$ ). A good reproduction of experimental data (Fig. 1) was obtained for $A$ in the range $1.5-3 \mathrm{~mm}$ and $\tau$ within $0.075-0.125 \mathrm{msec}$. For the following pairs of $A, \tau$, we obtained the highest fit quality: $3 \mathrm{~mm}$, $0.075 \mathrm{msec} ; 2 \mathrm{~mm}, 0.1 \mathrm{msec}$; and $1.5 \mathrm{~mm}, 0.125 \mathrm{msec}$. The reproduction of the $\mathrm{pH}$ dependence of the modeled mIPSCs was critically dependent on the time constant $\tau$; when this parameter was increased above 150-200 $\mu \mathrm{sec}$, the fit quickly deteriorated. For instance, for $\tau=300$ and $1000 \mu \mathrm{sec}(A=1.5 \mathrm{~mm})$ the quantitative reproduction of IIPSC $\mathrm{pH}$ dependence was poor, but the property that peak current shows a maximum at acidic $\mathrm{pH}$ was still present (compare Figs. $7 E, 1 D$ ). For the above mentioned values of $A$ and $\tau$, the model simulation allowed us to reproduce well the inhibition of synaptic currents at high proton concentration, an increase in amplitude at approximately $\mathrm{pH} 6.5$, and a minor effect on mIPSC amplitude at basic pH (Fig. 7D). Particularly striking was the opposite effect of strongly acidic $\mathrm{pH}$ values on amplitudes of mIPSCs (Fig. 1) and of current responses (Fig. 2 ). Our analysis provides an explanation for this apparent discrepancy. When $k_{\text {on }}$ is reduced, the receptor activation slows down, and the exposure to synaptic agonist transient becomes too short to activate the same number of channels as in control conditions. The apparent lack of effect on mIPSC amplitudes at basic $\mathrm{pH}$ seems to result from a mutual compensation of two factors: enhancement of receptor binding rate and increased entrance into the desensitized state $A_{2} D$.

\section{Discussion}

The major finding of the present work is a demonstration that protons affect the mIPSCs by modulating desensitization and the affinity of $\mathrm{GABA}_{\mathrm{A}}$ receptors.

Our analysis indicates that, at physiological $\mathrm{pH}$, saturating [GABA] activate only a minority of receptors (19\%) while remaining ones enter the desensitized conformation. This hypothesis is supported by the fact that a decrease in $\mathrm{pH}$ enhances responses to saturating [GABA] by several-fold whereas singlechannel conductance is not affected (Krishek and Smart, 2001). Our assessment of maximum open probability differs from those reported by other authors (in the range 0.5-0.8; Newland et al., 1991; Jones and Westbrook, 1995; Nusser et al., 1997, 2001; Mozrzymas et al., 1999; Perrais and Ropert, 1999; Barberis et al., 2000). The source of this discrepancy is not clear. A non-equilibrium analysis at the single-channel level will be required to elucidate this issue. 
Further arguments for crucial role of desensitization

As mentioned, desensitization plays an important role in shaping the GABAergic currents. Besides its impact on deactivation, the predictions of the model of Jones and Westbrook (1995) as well as of other investigators (Gingrich et al., 1995; Haas and Macdonald, 1999) indicate that desensitization may affect current amplitude. In the present work we further confirm this prediction and provide evidence that this effect is much stronger than what was predicted by previous models. In addition, we show that desensitization affects the onset of currents elicited by saturating [GABA]. We propose that such strong desensitization impact on $\mathrm{GABA}_{\mathrm{A}} \mathrm{R}$ kinetics reflects the fact that this process is the fastest ligand-independent transition (in control conditions). This is supported by a strong $\mathrm{pH}$ dependence of current amplitudes and desensitization kinetics (Figs. 2, 4; see Model simulations). An alternative explanation for the $\mathrm{pH}$ dependence of current amplitude could be alteration of the opening rate $\beta_{2}$. However, such a mechanism would lead to an accelerated onset of currents at acidic $\mathrm{pH}$, contrary to experimental observation (Fig. 2F).

\section{Effect of protons on $\mathrm{GABA}_{\mathrm{A}} \mathrm{R}$ affinity} shapes the responses to low [GABA] The analysis of the onset rate of currents (Fig. 5) evoked by nonsaturating [GABA] together with model simulations provided key evidence that the binding rate is enhanced by an increase in $\mathrm{pH}$. This was confirmed further by $\mathrm{pH}$ dependence of current amplitude evoked by very low [GABA] (Fig. 5D-F). Similarly, Pasternack et al. (1996) have observed that responses to low [GABA] are increased, whereas those evoked by high [GABA] are decreased when $\mathrm{pH}$ is increased and have attributed this finding to the presence of two receptor populations. Although in neurons such heterogeneity is quite likely, our data indicate a different explanation. As pointed out in Model simulations, at low [GABA] an increase in amplitude with $\mathrm{pH}$ is attributable to an increase in the binding rate, whereas at high [GABA] a decrease in amplitude reflects preferential entrance into the desensitized state $\left(d_{2} \gg\right.$ $\left.\beta_{2}\right)$.

\section{Modulation of $\mathrm{GABA}_{\mathrm{A}}$ receptor by protons reveals synaptic GABA transient}

Our analysis indicates that a striking difference in the amplitude $\mathrm{pH}$ dependencies of mIPSCs and current responses (Figs. 1, 2) results mainly from different agonist time courses in the two situations. Thus the hydrogen ions can be used as a convenient modifier of $\mathrm{GABA}_{\mathrm{A}} \mathrm{R}$ gating to probe the synaptic GABA tran$\mathrm{mm}, 0.125 \mathrm{msec}$.
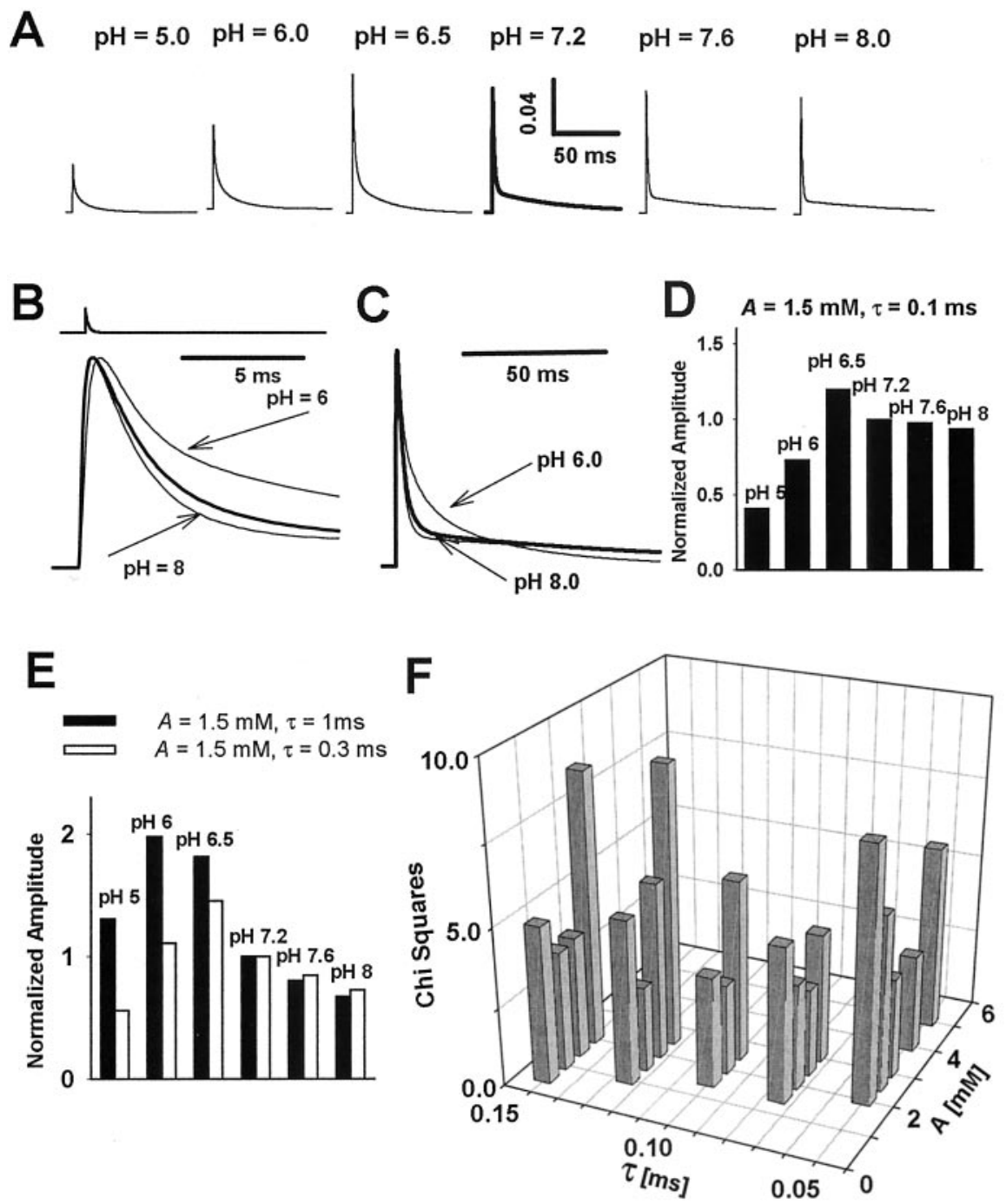

Figure 7. Model simulation of synaptic currents. Synaptic currents were simulated as current responses to exponentially decaying synaptic agonist transient $[A \cdot \exp (-\mathrm{t} / \tau)$, where $A$ is the peak concentration and $\tau$ is the time constant of agonist time scales for $\mathrm{pH} 6.0,7.2$ (thick line), and 8.0. The effect of proton concentration on the fast and slow component of the decaying phase qualitatively reproduces the experimental observations (compare with Fig. 1). D, pH dependence of the amplitudes of synaptic currents simulated for agonist transient described by $A=1.5 \mathrm{~mm}$ and $\tau=0.125 \mathrm{msec}$. This prediction well bars) and $1 \mathrm{msec}$ (filled bars). Note that in both cases the amplitude $\mathrm{pH}$ dependence shows a peak similar to that of synaptic (see Fig. 1D). F, Optimization of $A$ and $\tau$ parameters to best reproduce the $\mathrm{pH}$ dependence of mIPSCs. Standard $\chi^{2}$ to synaptic GABA application. The values of $A$ and $\tau$ parameters were varied to minimize the value of $\chi^{2}$ statistics. The highest fit quality (lowest $\chi^{2}$ statistics values) was obtained for the following $(A, \tau)$ parameters: $3 \mathrm{~mm}, 0.075 \mathrm{msec} ; 2 \mathrm{~mm}, 0.1 \mathrm{msec}$; and 1.5

sient. The time constant of agonist clearance estimated in the present study $(0.075-0.125 \mathrm{msec})$ was similar to that inferred in our previous work in which chlorpromazine was used as a modifier of gating (Mozrzymas et al., 1999). In the present study we were able additionally to assess the peak GABA concentration (1.5-3 mM) and to conclude that at physiological $\mathrm{pH}$ the mIPSCs are not saturating (when $A$ is increased from 2.5 to $10 \mathrm{mM}$, the amplitude of IPSC reaches saturation and increases by $\sim 50 \%$ ). Thus our data reinforce the view that GABAergic mIPSCs are not saturated (Frerking et al., 1995; Frerking and Wilson, 1996; Perrais and Ropert, 1999; Hajos et al., 2000; Nusser et al., 2001). 
Moreover, the proposed mechanism implies that acidification/ alkalization moves the activation conditions farther/closer from saturation.

Although it is possible that protons could affect mIPSCs by modulating synaptic GABA transient, it is unlikely that they could modify the diffusion coefficient (and therefore clearance) of GABA. Our data and model simulations (Figs. 6, 7) are consistent with the $\mathrm{pH}$ dependence of mIPSCs resulting from proton modulation of $\mathrm{GABA}_{\mathrm{A}}$ receptor gating with negligible effect on synaptic GABA transient. A contribution from proton effect on releasing mechanism, however, cannot be ruled out based only on electrophysiological data. Neurochemical approaches would help to elucidate this issue. The mechanism of presynaptic proton effect leading to the increase in mIPSC frequency is unknown and will be investigated in a separate study.

\section{Physiological significance}

The present study provides further evidence that $\mathrm{GABA}_{\mathrm{A}}$ receptors are highly sensitive to protons. We show that variation in the range of a few tenths of $\mathrm{pH}$ unit gives rise to significant modulation of the $\mathrm{GABA}_{\mathrm{A}}$ receptor (e.g., Figs. 2-4). It is known that such range of variation may occur in physiological (e.g., because of $\mathrm{HCO}_{3}^{-}$transport) (for review, see Kaila, 1994) and in pathological conditions such as epilepsy, ischemia, and hypoxia (Chesler, 1990; Chesler and Kaila, 1992). It is worth noting that, even if basic $\mathrm{pH}$ weakly affects mIPSC amplitudes (Fig. 1), the fact that receptors get closer to saturation may alter the susceptibility of mIPSCs to modulation by other drugs. In addition, the enhancement of $\mathrm{GABA}_{\mathrm{A}}$ receptor affinity at basic $\mathrm{pH}$ is expected to increase the shunting inhibition by ambient GABA.

\section{Validity of experimental approach and model}

In the present study the main body of evidence is derived from experiments on the outside-out patches that contain an unknown mixture of synaptic and extrasynaptic receptors. Moreover, the intracellular soluble messengers are lost after patch excision. However, it may be expected that the effects of protons on synaptic receptors and on those in patches excised from the same neurons are qualitatively similar. The fact that for both mIPSCs and current responses the rising and decaying phases showed similar kinetics and $\mathrm{pH}$ dependence (Figs. 1-3) supports this hypothesis.

In the present work we used a relatively simple model (Fig. $6 A$ ). In particular, fully bound slow desensitized states were not considered because they are believed to play a minor role in shaping the synaptic currents. On the other hand, the fact that similar kinetics of current responses could be reproduced by using considerably different sets of the rate constants (Barberis et al., 2000; this study) indicates model degeneration that can be reduced by including new experimental data. Key evidence enabling us to correct the rate constants was strong $\mathrm{pH}$ dependence of responses to saturating [GABA].

Previously, we have described the effects of chlorpromazine and zinc on microscopic gating of $\mathrm{GABA}_{\mathrm{A}} \mathrm{R}$ (Mozrzymas et al., 1999; Barberis et al., 2000). With the use of the present model, the effects of these drugs also could be well reproduced by manipulating the same rate constants as the model structure remains the same. In addition, it is possible that protons might affect the cooperativity of $\mathrm{GABA}_{\mathrm{A}}$ Rs binding sites, which recently was described in different preparations (Lavoie et al., 1997; McClellan and Twyman, 1999; Mozrzymas et al., 2003). However, most of proton effects are manifested at saturating [GABA] at which cooperativity (and binding in general) is not crucial.
Connections between singly and doubly bound open and desensitized states (Twyman et al., 1990; Jones et al., 1998) (classical model for AChR: Katz and Thesleff, 1957; Cachelin and Colquhoun, 1989) may affect the receptor kinetics. Moreover, recent studies (Chang et al., 2002; Scheller and Forman, 2002) have suggested an important role of connections between unbound and bound open and desensitized conformations. However, recordings performed by Chang et al. (2002) had the time resolution of seconds and therefore cannot be referred directly to the synaptic currents. Scheller and Forman (2002) found that connections between unbound and bound open and desensitized states were necessary for considered mutated receptors, whereas the wild type of channel was described satisfactorily by assuming a minor role of these transitions. This finding is compatible with analysis of Jones et al. (1998), who found that, in native receptors, rate constants for connections between singly and doubly bound desensitized states were orders of magnitude smaller than those connecting the closed states. It is worth noting that strong $\mathrm{pH}$ dependencies of amplitudes (Fig. 2) and desensitization (Fig. 4) provide further evidence for the prediction of the Jones and Westbrook model (1995) that the main "route" of receptor activation by saturating [GABA] is binding to closed states and then a bifurcation to the fully bound open and desensitized states. With the classical cyclic model (Katz and Thessleff, 1957; Chang et al., 2002) such proton effects (Figs. 2, 4) would be difficult to reproduce.

The present data indicate that the observed effects of protons result from an allosteric modulation of $\mathrm{GABA}_{\mathrm{A}}$ receptor macromolecules. However, the physical mechanism of these effects at molecular level remains an open question. Mutagenesis studies on recombinant receptors would be needed to address this issue.

\section{References}

Andjus PR, Stevic-Marinkovic Z, Cherubini E (1997) Immunoglobulins from motoneurone disease patients enhance glutamate release from rat hippocampal neurones in culture. J Physiol (Lond) 504:103-112.

Banks MI, Pearce RA (2000) Kinetic differences between synaptic and extrasynaptic $\mathrm{GABA}_{\mathrm{A}}$ receptors in CA1 pyramidal cells. J Neurosci 20:937-948.

Barberis A, Cherubini E, Mozrzymas JW (2000) Zinc inhibits miniature GABAergic currents by allosteric modulation of $\mathrm{GABA}_{\mathrm{A}}$ receptor gating. J Neurosci 20:8618-8627.

Berger T, Schwarz C, Kraushaar U, Monyer H (1998) Dentate gyrus basket cell $\mathrm{GABA}_{\mathrm{A}}$ receptors are blocked by $\mathrm{Zn}^{2+}$ via changes in their desensitization kinetics: an in situ patch-clamp and single-cell PCR study. J Neurosci 18:2437-2448.

Burkat PM, Yang J, Gingrich KJ (2001) Dominant gating governing transient $\mathrm{GABA}_{\mathrm{A}}$ receptor activity: a first latency and $P_{\mathrm{o} / \mathrm{o}}$ analysis. J Neurosci 21:7026-7036.

Cachelin AB, Colquhoun D (1989) Desensitization of the acetylcholine receptor of frog end-plates measured in a Vaseline-gap voltage clamp. J Physiol (Lond) 415:159-188.

Chang YC, Ghansah E, Chen Y, Ye J, Weiss DS (2002) Desensitization mechanism of GABA receptors revealed by single oocyte binding and receptor function. J Neurosci 22:7982-7990.

Cherubini E, Conti F (2001) Generating diversity at GABAergic synapses. Trends Neurosci 24:155-162.

Chesler M (1990) The regulation and modulation of $\mathrm{pH}$ in the nervous system. Prog Neurobiol 34:401-427.

Chesler M, Kaila K (1992) Modulation of $\mathrm{pH}$ by neuronal activity. Trends Neurosci 15:396-402.

Clements JD (1996) Transmitter time course in the synaptic cleft: its role in central synaptic function. Trends Neurosci 19:163-170.

Frerking M, Wilson M (1996) Saturation of postsynaptic receptors at central synapses? Curr Opin Neurobiol 6:395-403.

Frerking M, Borges S, Wilson M (1995) Variation in GABA mini amplitude is the consequence of variation in transmitter concentration. Neuron 15:885-895. 
Gingrich KJ, Roberts WA, Kass RS (1995) Dependence of $\mathrm{GABA}_{\mathrm{A}}$ receptor gating kinetics on the $\alpha$-subunit isoform: implications for structurefunction relations and synaptic transmission. J Physiol (Lond) 489:529-543.

Haas KF, Macdonald RL (1999) GABA $_{\mathrm{A}}$ receptor subunit $\gamma 2$ and $\delta$ subtypes confer unique kinetic properties on recombinant $\mathrm{GABA}_{\mathrm{A}}$ receptor currents in mouse fibroblasts. J Physiol (Lond) 514:27-45.

Hajos N, Nusser Z, Rancz EA, Freund TF, Mody I (2000) Cell type- and synapse-specific variability in synaptic $\mathrm{GABA}_{\mathrm{A}}$ receptor occupancy. Eur J Neurosci 12:810-818.

Jonas P (1995) Fast application of agonists to isolated membrane patches. In: Single-channel recording (Sakmann B, Neher E, eds), pp 231-243. New York: Plenum.

Jones MV, Westbrook GL (1995) Desensitized states prolong $\mathrm{GABA}_{\mathrm{A}}$ channel responses to brief agonist pulses. Neuron 15:181-191.

Jones MV, Sahara Y, Dzubay JA, Westbrook GL (1998) Defining affinity with the GABA receptor. J Neurosci 18:8590-8604.

Kaila K (1994) Ionic bases of $\mathrm{GABA}_{\mathrm{A}}$ receptor channel function in the nervous system. Prog Neurobiol 42:489-537.

Kaila K, Paalasmaa P, Taira T, Voipio J (1992) pH transients due to monosynaptic activation of $\mathrm{GABA}_{\mathrm{A}}$ receptors in rat hippocampal slices. NeuroReport 3:105-108.

Katz B, Thesleff S (1957) A study of the "desensitization" produced by acetylcholine at the motor end-plate. J Physiol (Lond) 138:63-80.

Krishek BJ, Smart TG (2001) Proton sensitivity of rat cerebellar granule cell $\mathrm{GABA}_{\mathrm{A}}$ receptors: dependence on neuronal development. J Physiol (Lond) 530:219-233.

Krishek BJ, Amato A, Connolly CN, Moss SJ, Smart TG (1996) Proton sensitivity of the $\mathrm{GABA}_{\mathrm{A}}$ receptor is associated with the receptor subunit composition. J Physiol (Lond) 492:431-443.

Krishek BJ, Moss SJ, Smart TG (1998) Interaction of $\mathrm{H}^{+}$and $\mathrm{Zn}^{2+}$ on recombinant and native rat neuronal $\mathrm{GABA}_{\mathrm{A}}$ receptors. J Physiol (Lond) 507:639-652.

Lavoie AM, Tingey JJ, Harrison NL, Pritchett DB, Twyman RE (1997) Activation and deactivation rates of recombinant $\mathrm{GABA}_{\mathrm{A}}$ receptor channels are dependent on $\alpha$-subunit isoform. Biophys J 73:2518-2526.

Maric D, Maric I, Wen X, Fritschy JM, Sieghart W, Barker JL, Serafini R (1999) $\mathrm{GABA}_{\mathrm{A}}$ receptor subunit composition and functional properties of $\mathrm{Cl}^{-}$channels with differential sensitivity to zolpidem in embryonic rat hippocampal cells. J Neurosci 19:4921-4937.

McClellan AML, Twyman RE (1999) Receptor system response kinetics reveal functional subtypes of native murine and recombinant human $\mathrm{GABA}_{\mathrm{A}}$ receptors. J Physiol (Lond) 515:711-727.
Mercik K, Zarnowska ED, Mandat M, Mozrzymas JW (2002) Saturation and self-inhibition of rat hippocampal $\mathrm{GABA}_{\mathrm{A}}$ receptors at high GABA concentrations. Eur J Neurosci 16:2253-2259.

Mozrzymas JW, Barberis A, Michalak K, Cherubini E (1999) Chlorpromazine inhibits miniature GABAergic currents by reducing the binding and by increasing the unbinding rate of $\mathrm{GABA}_{\mathrm{A}}$ receptors. J Neurosci 19:2474-2488.

Mozrzymas JW, Barberis A, Mercik K, Zarnowska E (2003) Binding sites, singly bound states, and conformation coupling shape GABA-evoked currents. J Neurophysiol 89:871-884.

Newland CF, Colquhoun D, Cull-Candy SG (1991) Single channels activated by high concentrations of GABA in superior cervical ganglion neurons of the rat. J Physiol (Lond) 432:203-233.

Nusser Z, Cull-Candy S, Farrant M (1997) Differences in synaptic GABA receptor number underlie variation in GABA mini amplitude. Neuron 19:697-709.

Nusser Z, Naylor D, Mody I (2001) Synapse-specific contribution of the variation of transmitter concentration to the decay of inhibitory postsynaptic currents. Biophys J 80:1251-1261.

Pasternack M, Smirnov S, Kaila K (1996) Proton modulation of functionally distinct $\mathrm{GABA}_{\mathrm{A}}$ receptors in acutely isolated pyramidal neurons of rat hippocampus. Neuropharmacology 35:1279-1288.

Perrais D, Ropert N (1999) Effect of zolpidem on miniature IPSCs and occupancy of postsynaptic $\mathrm{GABA}_{\mathrm{A}}$ receptors in central synapses. J Neurosci 19:578-588.

Puia G, Costa E, Vicini S (1994) Functional diversity of $\mathrm{GABA}_{\mathrm{A}}$-activated $\mathrm{Cl}^{-}$currents in Purkinje versus granule neurons in rat cerebellar slices. Neuron 12:117-126.

Robello M, Barduzzi R, Cupello A (2000) Modulation by extracellular pH of $\mathrm{GABA}_{\mathrm{A}}$ receptors expressed in Xenopus oocytes injected with rat brain mRNA. Int J Neurosci 103:41-51.

Scheller M, Forman SA (2002) Coupled and uncoupled gating and desensitization effects by pore domain mutations in $\mathrm{GABA}_{\mathrm{A}}$ receptors. J Neurosci 22:8411-8421.

Twyman RE, Rogers CJ, Macdonald RL (1990) Intraburst kinetic properties of the $\mathrm{GABA}_{\mathrm{A}}$ receptor main conductance state of mouse spinal cord neurones in culture. J Physiol (Lond) 423:193-220.

Voipio J, Paalasmaa P, Taira T, Kaila K (1995) Pharmacological characterization of extracellular $\mathrm{pH}$ transients evoked by selective synaptic and exogenous activation of AMPA, NMDA, and $\mathrm{GABA}_{\mathrm{A}}$ receptors in the rat hippocampal slice. J Neurophysiol 74:633-642.

Zhu WJ, Vicini S (1997) Neurosteroid prolongs GABA channel deactivation by altering kinetics of desensitized states. J Neurosci 17:4022-4031. 